\title{
Cycle Time Reduction in Shifting of Billet from Trio to Mill - Design for Roller Table
}

\author{
R Sasikumar \\ Assistant Professor, Department of mechanical Engineering \\ Ganesh College of Engineering - 636 111, Tamil Nadu. India. \\ M Ramakrishnan \\ Assistant Professor, Department of mechanical Engineering \\ Ganesh College of Engineering - 636 111, Tamil Nadu. India.
}

A Balamurugan

Assistant Professor, Department of mechanical Engineering

Ganesh College of Engineering - 636 111, Tamil Nadu. India.

A Gowrishankar

Assistant Professor, Department of mechanical Engineering

Ganesh College of Engineering - 636 111, Tamil Nadu. India.

\begin{abstract}
This paper was about the reduction of cycle time of transferring hot billet from the TRIO centre line to the MILL centre line. I used three methods of roller table to reduce the cycle time of transferring the hot billets. One method with inclined roller table to transfer billet satisfied out requirements and it successfully transferred the billet from TRIO centre line to MILL centre line. It was analyzed by SOLIDWORKS - Motion Study. The total time of transferring billet was reduced to continuous rolling time $18 \%$ and single hot billet total travel time reduced $25 \%$. The scratch line was highly reduced in hot billet and less maintenance of roller table addition advantage of inclined roller table is reduced billet scratch line and less maintenances.
\end{abstract}

Keywords: Hot billet; trial and error method; Roller table; SOLIDWORKS motion study.

\section{INTRODUCTION}

Bar and Rod mill is a semi-automated rolling mill having a capacity of 0.48 MTPA. The mill is designed to roll wide range of mild steel and alloy steel products. Steel billets of size $160 \mathrm{~mm}$ x $160 \mathrm{~mm}$ x $7 \mathrm{~m} \&$ variety of grades are charged on to the charging grid and fed into the re-heating furnace to heat it to a maximum of $1250^{\circ} \mathrm{C}$. After attaining the required temperature these hot billets are discharged from the furnace and fed into a three high mill (TRIO) for further reduction to $100 \mathrm{~mm} \times 100 \mathrm{~mm}$. Billet reduced at TRIO will be sent to continuous mill (Train 1, $2 \&$ 3) for further reduction to get the required finishing size at the Kocks Block. Bars/flats, leaving the Kocks Block/Continuous mill are divided by a dividing shear located after the continuous mill, fed into the cooling bed and further cut into 500 $\mathrm{T}$ cold shear. Finished product are bundled in the bundling station and stacked in the yard in respective location. Bars leaving the Kocks Block are finished at NTVM and they are wound in coil shape by the Laying Head which is guided by a pinch roll. The bottom end of the pipe revolves rapidly and forms the rod into rings that overlap in Spenserian form on to the stelmor conveyor where it can control the cooling rate of the coil with the help of blowers. The coils are carried through the conveyor and the coils are loaded to the ' $\mathrm{C}$ ' hook conveyor by means of Coil Transfer car and they are cooled to ambient temperature after passing through a conveyor consisting of 100 no's of ' $\mathrm{C}$ ' hooks. These coils are inspected, end trimmed, compacted, bound/strapped and unloaded from the conveyor. Coils are then stacked at the stacking yard at the designated places. These hot coils are handled with the help of a plate conveyor Above the Table 1 the production cycle time in BRM.

\section{Table 1: Cycle Time of Billets}

\begin{tabular}{|c|l|l|}
\hline Rolling & \multicolumn{1}{|c|}{ Bar \& Rod } & \multicolumn{1}{c|}{ Coil } \\
\hline Continuous rolling time & $56 \mathrm{sec}$ to $60 \mathrm{sec}$ & $75 \mathrm{sec}$ to $80 \mathrm{sec}$ \\
\hline
\end{tabular}




\begin{tabular}{|l|l|l|}
\hline Single billet running time & 2 mins & $2.5 \mathrm{mins}$ \\
\hline
\end{tabular}

\section{PROBLEMS IDENTIFIED}

While visiting the plant, the major problem that I noticed was the rejection of billet due to some issues in the offline route. Rejection was usual in the rolling mill. The problem is the time taken to get back the rejected billet from the line. There is a system called IMF (Intermediate Furnace), where the billets are stored for a moment and there the fingers are used to lift the billets from the TRIO centre to the mill centre. There it takes more time. This delay in shifting the billet takes much time and it highly affects the production rate of the plant.

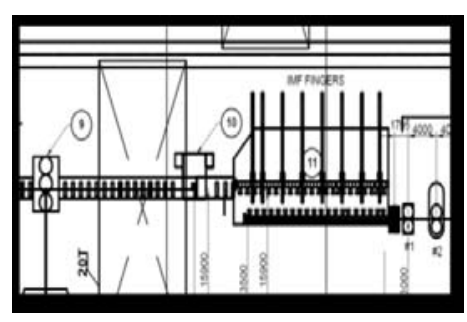

Figure1: IMF Layout.

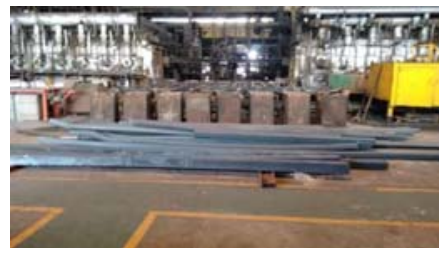

Figure 2 Front End Hit Rejected Billets Billets

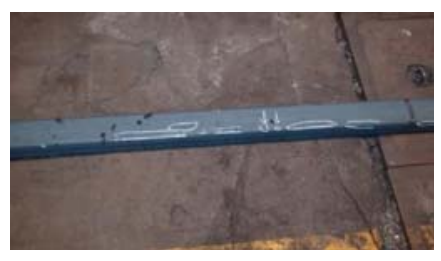

Figure 3 Scratch Line Rejected

The above Figure 1 clearly shows the layout of the IMF and its finger alignment and their mechanisms. Time delay in IMF due to shifting of billets. The fingers are usually getting misaligned and it has to be rectified often. There is a possibility of wear and tear of the shaft that is used as finger. The rollers need some special set up to work properly. Front end hit and scratch line occurred in the billets.

Rolling Bar \& Rod Coil Continuous rolling time $56 \mathrm{sec}$ to $60 \mathrm{sec} 75 \mathrm{sec}$ to $80 \mathrm{sec}$ Single billet running time 2 mins 2.5 mins. The Figure 2 shows the billet that get rejected in the IMF due to the front end hit and bent and it is been kept aside using crane and it takes some time and it causes delay in the production. The Figure 3: clearly shows the scratch line that observed while transferring the billet from the IMF charging end to the discharging end. It is been rejected and kept for inspection for the reason for its rejection. These are the problems identified in the plant and the methodology to reduce the cycle time delay in the IMF is explained in the next chapter.

\section{METHODOLOGY}




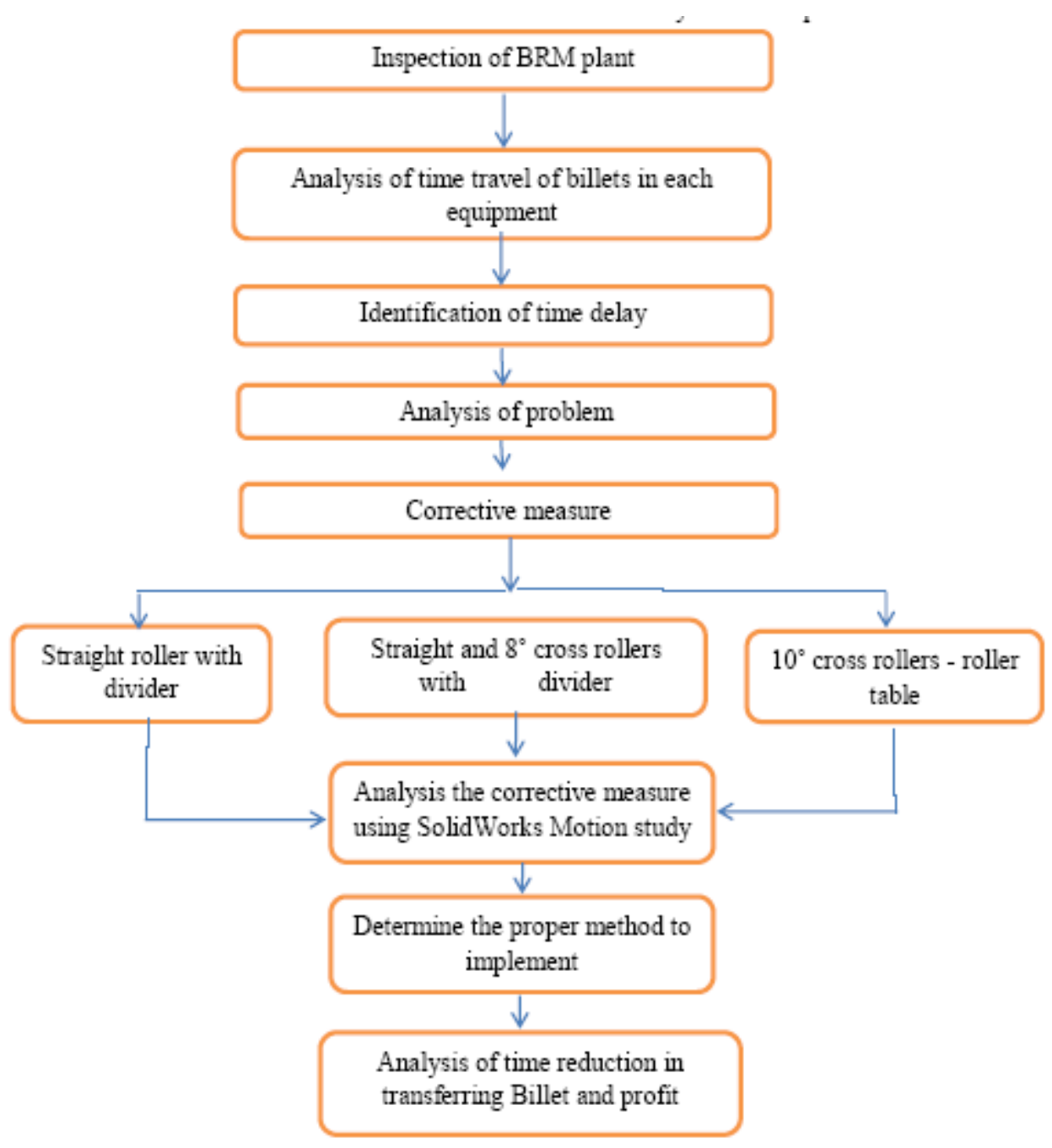

Figure 4 Process Layout

As discussed earlier in the previous chapter, there are lot of problem in shifting the billets from the TRIO centre line to the mill centre line. The problem can be rectified by changing the IMF system. Form the TRIO the billets were framed to reach the mill centre line by some techniques, which are to be discussed later in this chapter. The project was carried out with trial and error method. I planned to carry out this project with deflector plate initially and later with taper rollers with some inclination. Those methods are to be discussed briefly in this chapter.

\subsection{ANALYSIS OF TIME TRAVEL OF BILLETS}

The time travel of the billet in each equipment of the plant is analysed for all the three routes. In each route the time travel of the billets vary according to the size of the final product. In cooling bed route, the billets travels much faster as the equipment are lesser and the size of the final outcome is larger and it varies from $20 \mathrm{~mm}$ to $60 \mathrm{~mm}$. In wire rod mill, the travel of the billets are longer as it contains many equipment and the size of the product is smaller and it varies from $5.5 \mathrm{~mm}$ to $15 \mathrm{~mm}$. Similarly, in Garret Coiler route, the time travel of the billet is longer.

\subsection{IDENTIFICATION OF TIME DELAY}

There is also some time delay in the online route/mill area, especially in the IMF. There the billets from the TRIO centre line are transferred to the mill centre line. These transfer of billets are by the special arrangement in the 
IMF. It contains charging roller table and discharging roller table. It also has some finger arrangements and it helps in shifting the billets from the charging roller table to the discharging roller table.

\subsection{CORRECTIVE MEASURE}

From the study of the time delay, I planned to overcome the delay in the IMF area, where the delay is more. The corrective measures are carried out by trial and error method. I planned to overcome the delay by trailing the following methods.

- Straight roller with divider.

- Straight and $8^{\circ}$ cross rollers with divider.

- $10^{\circ}$ cross rollers - roller table.

\subsubsection{STRAIGHT ROLLER WITH DIVIDER}

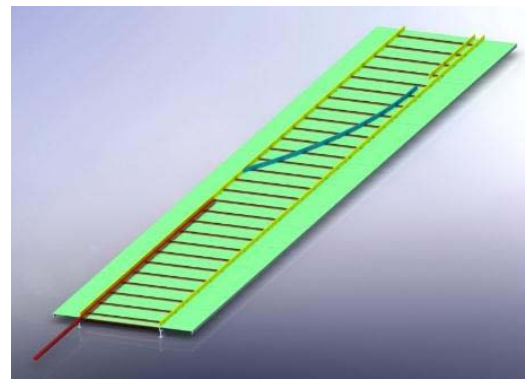

Figure 5:

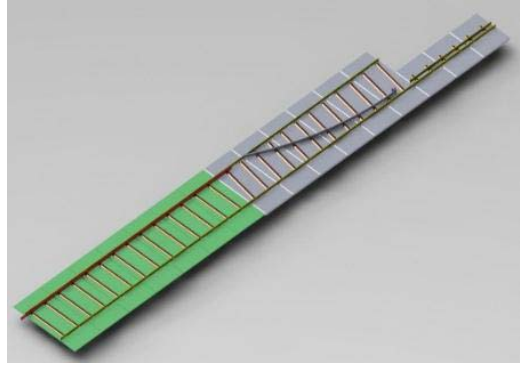

Figure 6:

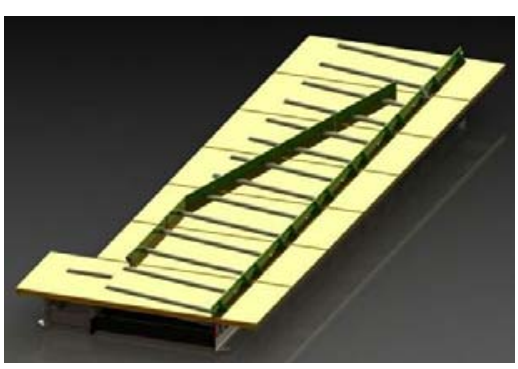

Figure 7:

Figure 5: Straight roller with divider, Figure 6: Straight and $8^{\circ}$ cross rollers with divider Figure 7: $10^{\circ}$ cross rollers roller table

In this method, Figure 5 shown the rollers are straight (no inclination), where the dividers are used to navigate the travelling billets from the TRIO centre line to the mill centre line. The divider plates were used at three positions throughout the roller table, as it paves the way for the billets to travel. The divider deflects the billets and it made it to transfer to the mill centre line.

\subsubsection{STRAIGHT AND $8^{\circ}$ CROSS ROLLERS WITH DIVIDER}

In this method, some rollers are inclined with $8^{\circ}$ with the divider and it followed by the straight rollers. Figure 6 shown the inclined rollers brought the billet from the TRIO center line to the mill center line. The deflector plate helps the billet not to escape from the table and also for the deflection of the billet to the mill center line.

\subsection{3. $10^{\circ}$ CROSS ROLLERS - ROLLER TABLE}

In this method, all the rollers in the roller table are inclined to an angle of $10^{\circ}$. This inclined rollers brought the rollers from the TRIO center line to the mill center line Figure 7 there is also a guard plate which is placed aside as a deflector plate and it helps in preventing the plate not to escape from the roller table and also pave the way for the billet to reach the mill centre line.

\subsection{ANALYSIS OF IDENTIFIED SOLUTION}

The three corrective measures were analysed using SOLIDWORKS - MOTION STUDY (2014). It clearly shows the possibility of the travel of billets through the roller table. The actual dimensions and the material 
characteristics and their parameters were fed. It generated the result of the three methods of transferring the billets from the TRIO centre line to the mill centre line. Actual dimensions of the billet and the roller table are fed in it. The outcome from the motion study were studied and it helps in the implementation of the roller table in the real time application. The three methods were analysed using this software and it was designed.

\subsection{PROPER METHOD OF IMPLEMENTATION}

From the above three methods, after analysing in the motion study, the result is obtained and it is converted in the form of the video. The screen-shots of the video clearly show the correct method to carry out the project. The proper method of implementation of the project is discussed in the next chapter. $10^{\circ}$ cross rollers - roller table method was the apt one for this project, as the billet front and tail end travels along the roller table.

\subsection{ANALYSIS OF TIME REDUCTION AND PROFIT}

From the corrective measure, the time reduction in the transferring of the billet is predicted and the profit made were calculated. Those details were explained in the next chapter. The reduction in time and profit were predicted based on the proper method that found using the solid works motion study. The detailed discussion of the results were discussed in the next chapter.

\section{RESULT AND DISCUSSION}

\subsection{MOTION STUDY From the SOLIDWORKS - MOTION STUDY,}

three methods were analysed and it helps in determining the correct method to carry out the project. I planned to overcome the delay in the IMF area, where the delay is more. The corrective measures are carried out by trial and error method. I planned to overcome the delay by trailing the following methods:

- Straight roller with divider.

- Straight and $8^{\circ}$ cross rollers with divider.

- $10^{\circ}$ cross rollers - roller table.

These were the three methods that I worked in motion study to check the possibility of travel of billets over the roller table.

\subsection{STRAIGHT ROLLER WITH DIVIDER}

Figure 8 clearly shows that the billet hit the side guide plate and it cannot be preceded further. The straight rollers with the deflector plate cannot be used in IMF to transfer the billet from the TRIO centre line to the mil centre line. Hence, this method fails to meet our circumstances of transferring the billet.

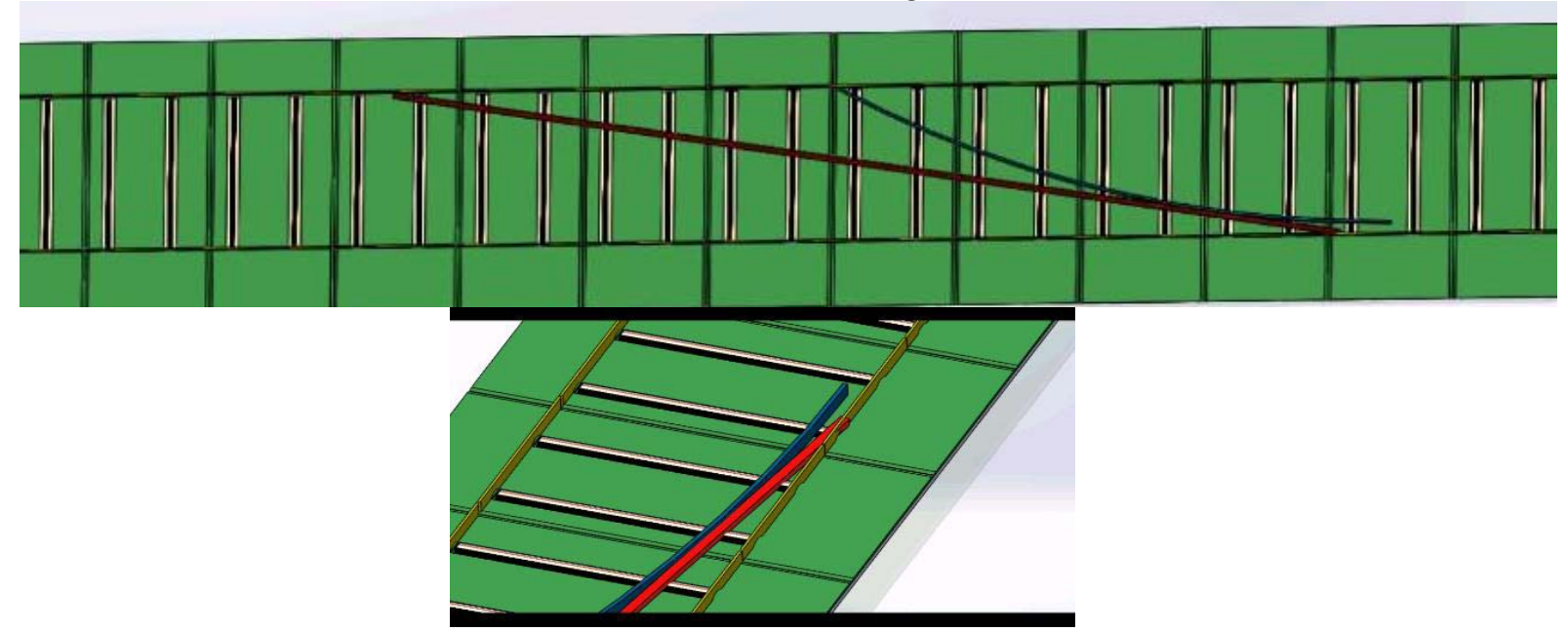


Figure 8 Error in Straight Roller with Divider

The Straight roller with divider over hit for billet front end - front end bend, and scratch line come. Billet not shift to IMF discharge side, - failure.

\subsection{STRAIGHT AND $8^{\circ}$ CROSS ROLLERS WITH DIVIDER}
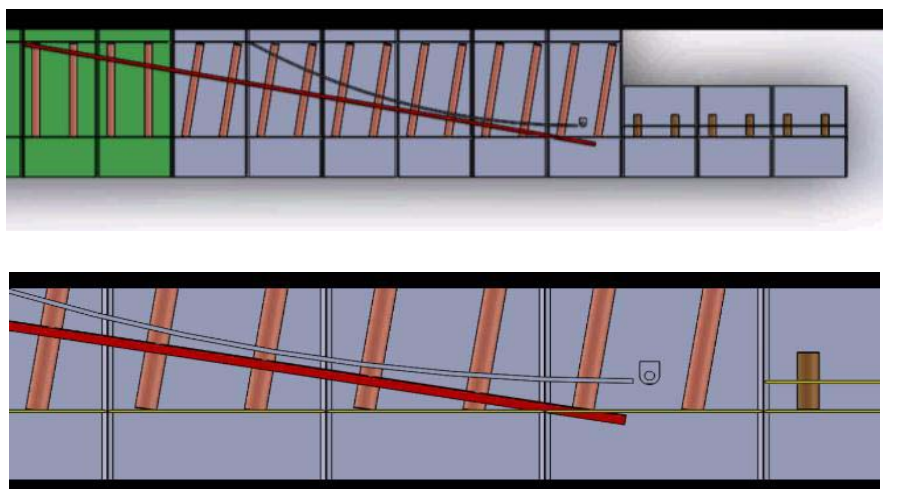

Figure 9 Error in Straight And $8^{\circ}$ Cross Rollers with Divider.

The Figure 9 shows the error in transferring the billet by straight and $8^{\circ}$ cross rollers with divider. The front end hits and escapes out the side guide plate. It needs additional inclined roller or the even more inclination in the roller. Hence, it was also not met our need to transfer the billet from the TRIO centre to the mill centre line. $8^{\circ}$ cross roller with divider divider circular shape so billet accurate turn and shift for IMF discharge side, and same time this roller $8^{\circ}$ crossed and only for 12 roller only. Billet front end over hit for guide plate. Scratch line, front end bending, not shifting, - failure.

\section{4. $10^{\circ}$ CROSS ROLLERS - ROLLER TABLE}
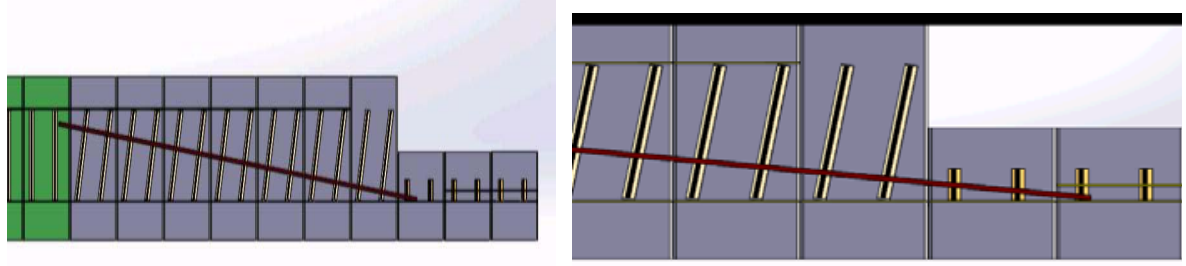

Figure $10.10^{\circ}$ Cross Rollers - Roller Table

From the above Figure 10 we came to conclusion that $10^{\circ}$ cross rollers can sufficiently meets our requirements of transferring the billets. The front end and tail end had some clearance with the side guide plate and from divider. Hence, this method can be used for implementation of the project. Hence, we can reduce the time delay in the IMF due to transferring of the billet. This method helps not only in reduction of time but also in the removing scratch line defect of rejecting billets. So, this method can be used to implement the system in the plant. $10^{\circ}$ cross roller - roller table in this roller table 14 rollers is crossed to $10^{\circ}$. Billet was shifted to IMF discharge side, without help of divider. No scratch line, billet bending, Billet travel cycle time reduced $12-15$ sec.

Table 2: Time Reduction in Continuous Rolling

\begin{tabular}{|c|c|c|c|c|c|}
\hline Product & Contents & Existing System & $\begin{array}{c}\text { Modified } \\
\text { System }\end{array}$ & Time Reduction & $\begin{array}{c}\% \text { Time } \\
\text { Reduced }\end{array}$ \\
\hline
\end{tabular}




\begin{tabular}{|c|c|c|c|c|c|}
\hline Bar \& Rod & \multirow{2}{*}{ Time (Sec) } & $56-60$ & $46-48$ & $10-12$ & $18 \%$ \\
\cline { 3 - 5 } Coil & $75-80$ & $65-68$ & $10-12$ & $18 \%$ \\
\hline
\end{tabular}

From the above Table 2: we can come to conclusion that the time travel of the billets in IMF is reduced to $18 \%$ (10-12 secs). This much of reduction in the time of travel of billets in the IMF would bring better production and the profit. Hence the oil consumption in the furnace would also become lesser and it also brought some profit to the concern.

Table 3: Time Reduction in Billet Total Travel Time

\begin{tabular}{|c|c|c|c|c|c|}
\hline Product & Contents & $\begin{array}{c}\text { Existing } \\
\text { System }\end{array}$ & Modified System & Time Reduction & $\begin{array}{c}\text { \% Time } \\
\text { Reduced }\end{array}$ \\
\cline { 1 - 4 } Barr \& Rod & \multirow{2}{*}{ Time (Sec) } & 120 & 90 & 30 & $25 \%$ \\
\cline { 1 - 4 } Coil & 150 & 120 & 30 & $25 \%$ \\
\hline
\end{tabular}

From the above Table 3: we come to conclusion that the time travel of the billets in IMF was much reduced to $25 \%$. Hence, time travel of billets was much reduced and it also bring profit to the industry.

\section{CONCLUSION}

In this project, the total cycle time of transferring billet is reduced. The project was carried out with trial and error method. The three methods were discussed and the correct method to implement the project was found using the SOLIDWORKS - Motion Study. It clearly shows that the inclined rollers of $10^{\circ}$ would make the billet to reach the billet from the TRIO center line to mill center line. Finally, I predicted that this method would reduce the cycle time to $18-25 \%$. This method would reduce the scratch line reduce the billet rejections. The design for the $10^{\circ}$ inclined rollers, assembly and its base set-up were designed. Hence, there will not be any rejections in the IMF. IMF will be completely removed with its pumping system and hence, there will not be any delay in it and maintenance cost will be reduced much. This project will help the concern to increase its productivity, profit, and the quality of the product.

\section{ACKNOWLEDGEMENT}

I thank the management for hearing granted Permission to do our project in JSW Steel Limited, Salem. We would like to thank for allowing us to take up this project under them.

\section{REFERENCES}

[1] 1. Ashveer sing., Shashank P Joshi., and Ronak R. Patel., (2015) “A Review on Design of Live Roller Conveyor System”, International Journal of Science Technology \& Engineering, Vol. 1, Issue 11, pp. 041.

[2] 2. Gaikwad S.S. and E.N. Aitavade., (2013) "Static analysis of roller of gravity roller conveyor for structure strength \& weight optimization", International Journal of Advanced Engineering Technology, Vol. 7, pp. 27-30.

[3] 3. Nannaware D.K. and Kharde R.R., (2014) "Design and Optimization of Roller Conveyor System", International Journal of Advanced Engineering Research and Studies, Vol. 5, Issue 7, pp. 1254-1258.

[4] 4. Suhas M., Shinde and Patil R.B., (2012) "Design and analysis of a roller conveyor System for Weight Optimization and Material saving", International Journal of Advanced Engineering Technology, Vol. 3, pp. 168-173.

[5] 5. Yogesh Tanajirao Padwal., Satish M. Rajmane., and Swapnil S. Kulkarni., (2013) "Design and analysis of a roller conveyor for weight optimization \& material saving", International Journal of Advanced Engineering Research and Studies, Vol. 4, pp. 138-140. 